\title{
Epiphyseal Necrosis in Patients with HIV Infection and Free from Sickle Cell Disease
}

\section{Koffi-Tessio Viwalé ES ${ }^{1}$, Houzou Prénam² ${ }^{2}$ Kakpovi Kodjo ${ }^{1}$, Fianyo Eyram³ , Oniankitan Owonayo ${ }^{3}$ and Mijiyawa Moustafa ${ }^{1 *}$}

${ }^{1}$ Department of Rheumatology, University Hospital Sylvanus Olympio of Lomé, Lomé, Togo

${ }^{2}$ Department of Rheumatology, University Hospital of Kara, Kara, Togo

${ }^{3}$ Department of Rheumatology, CHR Lomé-Commune, Lomé, Togo

*Corresponding author: M Mijiyawa, Rheumatology Department, University Hospital Sylvanus Olympio of Lomé, Togo, E-mail: mijiyawa@tg.refer.org

Received date: December 26, 2017; Accepted date: January 05, 2018; Published date: January 11, 2018

Citation: Koffi-Tessio Viwale ES, Houzou P, Kakpovi K, Fianyo E, Oniankitan O, et al. (2018) Epiphyseal Necrosis in Patients with HIV Infection and Free From Sickle Cell Disease. J Autoimmune Disord Vol.4 No.1: 01.

Copyright: (02018 Viwalé ESKT, et al. This is an open-access article distributed under the terms of the Creative Commons Attribution License, which permits unrestricted use, distribution, and reproduction in any medium, provided the original author and source are credited.

\section{Abstract}

We report a series of 17 cases of epiphyseal necrosis observed in nine women aged 40 years on average. These nine patients, with HIV1 infection, were free from other risk factors of bone necrosis, especially SS and sickle cell disease. The necrosis affected the two femoral heads in 6 patients, one femoral head in one patient, one humeral head in one patient, and the two femoral heads and one humeral head in the last patient. The necrosis revealed HIV1 infection in 4 patients. It has complicated the course of HIV1 infection in other 5 patients, despite antiretroviral therapy.

These observations argue in favor of the etiological role of HIV infection in the occurrence of epiphyseal necrosis. The relatively young age of the patients and the high number of bilateral involvement testify to the severity of the necrosis induced by HIV.

Keywords : Bone; Necrosis; HIV; Africa

\section{Introduction}

The femoral head is the most affected epiphysis by bone necrosis. Factors favouring necrosis of the femoral head are mainly represented by sickle cell disease, diabetes, alcoholism, corticotherapy, dyslipidaemia, aeroembolism, systemic lupus erythematosus, and upper extremity trauma of the femur $[1,2]$. In sub-Saharan Africa, hemoglobinopathies are by far the most important etiological factor of this necrosis, which is one of the most serious functional complications [3-6]. Over the past 20 years, the list of risk factors for bone necrosis has been enriched by HIV infection. The incidence of avascular necrosis in HIV patients is greater than the general population. The pathogenesis of bone necrosis associated with HIV infection remains to be elucidated [7-10]. We report 17 cases of epiphyseal necrosis in nine women infected by HIV1, and free from sickle cell disease.

\section{Patients and Methods}

The nine patients underwent a rheumatologic consultation which resulted in the diagnosis of epiphyseal necrosis, established by imaging, after the clinical examination. Explorations for a risk factor for epiphyseal necrosis were then carried out (alcoholism, past pelvic trauma, diabetes, sickle cell disease, corticosteroid therapy, dyslipidemia, HIV infection).

\section{Observations}

The first observation is that of a 47-year-old nurse with a duodenal ulcer by endoscopic diagnosis in 1987, and whose consultation was motivated by pain in the groins, which had been evolving for 2 years and irradiating to the knees. To these pains, a reduction of the walking perimeter to 50 meters was associated. These pains are symptomatic of aseptic necrosis of the femoral heads in stage IV revealed by CT scan. HIV1 infection was the only found risk factor.

The second case is that of a 27-year-old student with HIV1 infection known three years and treated since then with antiretrovirals. She has since suffered from pains in the groins irradiating to the lower limbs. These pains, with an inflammatory schedule, are associated with limping gait, a reduction in the perimeter of walking to a few meters, and a limitation of the mobility of the hip joints. They were related to a necrosis of the femoral heads stage III by X-ray. No other risk factors for necrosis were identified during paraclinic examinations.

The third case is that of a 37-year-old housewife whose pains in the root of the lower limbs irradiating to the thighs were related to a stage III necrosis of the femoral heads. The etiological investigation revealed an infection by HIV1, the only risk factor found. 
In the fourth patient, 38-year-old, groin pains for two years were symptomatic of the necrosis of the femoral heads, which was revealed by X-ray (Stage III at the right side and Stage II at the left). This necrosis was indicative of a retroviral infection by HIV1 which was the only risk factor found.

The fifth patient is a 50-year-old trader, who has been infected by HIV1 known eight years ago and has been on antiretroviral therapy since then. The necrosis of the left femoral head stage IV, revealed by CT Scan, resulted in groin pains and limping gait evolving for two years and requiring the use of a cane.

The sixth observation is that of a 40 -year-old nurse who has been infected with HIV1 for nine years and has since been treated with antiretrovirals. Two types of pain, which started a year ago, motivated the patient's rheumatologic consultation: pain in the right shoulder hampering movement, and inflammatory pain in the lower limb roots dating back a year and irradiating to the knees. These pains were associated to a necrosis of the right humeral head and of femoral heads after radiographic examination. No other risk factor for bone necrosis was demonstrated by paraclinical examinations.

The seventh observation is that of a 50 -year-old nurse with NSAID-induced epigastralgia who underwent salpingectomy and breast aesthetic surgery in 2005. She has been treated with antiretrovirals since October 2013 for HIV1 infection detected 11 years earlier. The consultation of this patient was motivated by a necrosis of the femoral heads (stage II) objectified by standard radiography.

The eighth case is that of a 34-year-old teacher, with HIV1 infection, known since 5 years, and undergoing an antiretroviral therapy since then. She consulted in April 2014 for a mechanical pain of the left shoulder evolving for 6 months and hampering the movements of rotation, abduction and retropulsion. The standard X-ray showed an osteonecrosis of the humeral head.

The last case is that of a 58-year-old woman, suffering for two years from bilateral trochanteric pain of mixed schedule and disabling for 3 weeks, symptomatic of a necrosis of femoral heads objectified by radiography. HIV1 infection was the only associated risk factor found.

In addition to the absence of usual risk factors for epiphyseal necrosis, the nine female patients, all HIV1 infected, had a biological inflammatory syndrome despite general condition keeping (body mass index between 17 and $39 \mathrm{~kg} / \mathrm{m}^{2}$, erythrocyte sedimentation rate between 34 and $120 \mathrm{~mm} / \mathrm{h}$, a hemoglobin concentration between 9 and $10 \mathrm{~g} / \mathrm{dl}$ ), and a CD4 level between 73 and 667 per microliter.

\section{Discussion}

The nine cases reported in this series were all women, aged 40 years on average, corresponding to a total of 17 epiphyseal necrosis (15 located at the femoral head, 2 located at the humeral head). The necrosis was indicative of HIV1 infection in 4 patients, and complicated the progression of it in the other 5 , despite antiretroviral therapy. The relatively young age of the patients and the high number of bilateral involvement testify to the severity of the necrosis induced by HIV.
Though related to a short series, the reported findings support the etiological role of HIV infection in epiphyseal necrosis. This role remains dominated by sickle cell disease, responsible for $70 \%$ of femoral head necrosis and $45 \%$ of hip diseases in prior studies conducted in Lomé [11]. This predominant etiological role, established in many other countries and regions of Africa, is explained by the high prevalence of sickle cell disease [3-5].

Avascular necrosis is an emerging complication of HIV infection. The association of avascular necrosis and HIV infection was established in Europe and Asia, in adults as well as in children [1,10,12-15]. The prevalence of asymptomatic hip necrosis in HIV patients was $41 \%$ in a study conducted in Spain [12]. Patients infected with HIV have an unexpectedly high occurrence of osteonecrosis of the hip. After an observation of 3250 person-year, 11 of 967 (11\%) HIV-infected patients at a median age of 34 years, developed osteonecrosis of hip joints, in a study conducted in Taiwan [15]. Although screening asymptomatic patients is not warranted, HIV-infected patients with persistent groin or hip pain should be evaluated for this debilitating complication [13]. But, this association has rarely been reported in sub-saharian Africa. The mechanisms by which HIV induces epiphyseal necrosis are complex. Both role of HIV and antiretroviral therapy are evocated $[1-3,15]$. High serum IgE levels and loss of working ability in advance of osteonecrosis appeared for the first time as possible predictors of osteonecrosis in HIV patients, while long-term exposure to steroids, combined hyperlipemia and chronic treatment with other drugs in addition to antiretrovirals were confirmed. Predicting and preventing osteonecrosis in HIV-infected patient are therefore a clinically challenging opportunity $[10,16]$

In sub-saharian Africa, the long-term follow-up will help assess the exact profile of the necrosis induced by HIV infection. Subsequent studies will also help provide a description of the semiological and evolutionary profile of necrosis in the subject with both sickle cell disease and HIV infection.

\section{References}

1. Liu F, Wang W, Yang L, Wang B, Wang J, et al. (2017) An epidemiological study of etiology and clinical characteristics in patients with nontraumatic osteonecrosis of the femoral head. J Res Med Sci 16: 15.

2. Guerado E, Caso E (2016) The physiopathology of avascular necrosis of the femoral head: an update. Injury 47: S16-S26.

3. Naseer ZA, Bachabi M, Jones LC, Sterling RS, Khanuja HS (2016) Osteonecrosis in Sickle Cell Disease. South Med J 109: 525-530.

4. Matos MA, Dos Santos Silva, Brito Fernandes R, Dias Malheiros C, Pinto da Silva BV (2012) Avascular necrosis of the femoral head in sickle cell disease patients. Ortop Traumatol Rehabil 14: 155-160.

5. Mahadeo KM, Oyeku S, Taragin B, Rajpathak SN, Moody K, et al (2011) Increased prevalence of osteonecrosis of the femoral head in children and adolescents with sickle-cell disease. Am J Hematol 86: 806-808

6. Van Tuijn CFJ, Schimmel M, Van Beers EJ, Nur E, Biemond BJ (2017) Prospective evaluation of chronic organ damage in adult sickle cell patients: A seven-year follow-up study. Am J Hematol 92: E584E590.

This article is available from: http://autoimmunediseases.imedpub.com 
7. Borges ÁH, Hoy J, Florence E, Sedlacek D, Stellbrink HJ, et al. (2017) Antiretrovirals, Fractures, and Osteonecrosis in a Large International HIV Cohort. Clin Infect Dis 64: 1413-1421.

8. Mehsen-Cêtre N, Cazanave C (2015) Osteoarticular manifestations associated with HIV infection. Joint Bone Spine 84: 29-33.

9. Cummins F, Ramasubbu B, McCarthy T, Bergin C, Grieve PP. Surgery of the femur in HIV positive patients : a retrospective review from 2005 to 2011. Ir J Med Sci 184: 505-510.

10. Mazzotta E, Agostinone A, Rosso R, Di Biagio A, De Socio GV, et al. (2011) Osteonecrosis in human immunodeficiency virus (HIV)infected patients: a multicentric case-control study. J Bone Miner Metab 29: 383-388.

11. Mijiyawa M, Pfudie S, Pitche V, N'Dakena K, Amedegnato MD, et al. (1994) Doury P. Coxofemoral pathology in rheumatology consultation in Togo. Med Trop (Mars) 54: 38-42.

12. Lamas JL, Ocampo A, Martínez-Vázquez $C$, Miralles $C$, Longueira $R$, et al. (2010) Asymptomatic osteonecrosis of the hip in HIV infected patients]. Enferm Infecc Microbiol Clin 28: 150-155.
13. Miller KD, Masur H, Jones EC, Joe GO, Rick ME, et al. (2002) High prevalence of osteonecrosis of the femoral head in HIV-infected adults. Ann Intern Med 137: 17-25.

14. Gaughan DM, Mofenson LM, Hughes MD, Seage GR, Ciupak GL, et al. (2002) Pediatric AIDS Clinical Trials Group Protocol 219 Team.Osteonecrosis of the hip (Legg-Calvé-Perthes disease) in human immunodeficiency virus-infected children. Pediatrics 109: E74-4.

15. Ho YC, Shih TT, Lin YH, Hsiao CF, Chen MY, et al. (2007) Osteonecrosis in patients with human immunodeficiency virus type 1 infection in Taiwan. Jpn J Infect Dis 60: 382-386.

16. Whitlock GG, Herbert S, Copas A, Gilson R, Ainsworth JG (2013) Avascular necrosis I HIV patients : a case-contol study. Int J STD AIDS 24: 799-803. 